Keywords: $M C U, A R P, I S D P$

Retention: Permanent

\title{
Supplemental Analyses for Solvent Hold Tank Samples MCU-11-314, MCU-11-315, MCU-11-316, MCU-11-317, MCU-11-318 and MCU-11-319
}

T. B. Peters

A. L. Washington, II

F. F. Fondeur

S. D. Fink

September 2011

Savannah River National Laboratory Savannah River Nuclear Solutions

Aiken, SC 29808

Prepared for the U.S. Department of Energy under

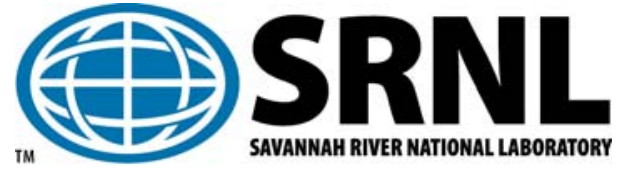
contract number DE-AC09-08SR22470. 
SRNL-STI-2011-00591

Revision 0

\section{DISCLAIMER}

This work was prepared under an agreement with and funded by the U.S. Government. Neither the U.S. Government or its employees, nor any of its contractors, subcontractors or their employees, makes any express or implied:

1. warranty or assumes any legal liability for the accuracy, completeness, or for the use or results of such use of any information, product, or process disclosed; or

2. representation that such use or results of such use would not infringe privately owned rights; or

3. endorsement or recommendation of any specifically identified commercial product, process, or service.

Any views and opinions of authors expressed in this work do not necessarily state or reflect those of the United States Government, or its contractors, or subcontractors.

\section{Printed in the United States of America}

Prepared for

U.S. Department of Energy 


\section{REVIEWS AND APPROVALS}

\section{AUTHORS:}

T. B. Peters, Author, SRNL/SASP

Date

A. L. Washington, II, Co-author, SRNL/ACP

Date

F. F. Fondeur, Co-author, SRNL/SASP

Date

TECHNICAL REVIEW:

K. M. Taylor-Pashow, Technical Reviewer, SRNL/ SASP

Date

APPROVAL:

S. D. Fink, SRNL/SASP, Coauthor and Manager

Date

S. L. Marra, SRNL/E\&CPT Research Programs, Manager

Date

D. J. Martin, H Tank Farm Process Engineering

Date 


\section{EXECUTIVE SUMMARY}

Savannah River National Laboratory (SRNL) periodically analyses solvent samples from Modular Caustic-Side Solvent Extraction Unit (MCU) in support of continuing operations. A quarterly analysis of the solvent is required to maintain solvent composition within specifications. Analytical results of the analyses of Solvent Hold Tank (SHT) samples MCU-11-314, MCU-11-315, MCU-11-316, MCU-11-317, MCU11-318 and MCU-11-319 have been previously reported. ${ }^{1}$

MCU has experienced a modest decline in cesium removal efficiency while processing the current feed, "Macrobatch 3". While the target decontamination factor (DF) is 200, the fiscal year 2011 DF average is 161. The results of the prior solvent analysis report did not identify a specific factor that would correlate with the poor cesium decontamination beyond a low concentration of the suppressor, trioctylamine. New analyses of the quarterly sample are reported in this document, as well as a cross-check of ${ }^{137} \mathrm{Cs}$ measurements for SRNL and F/H lab.

Furthermore, in an attempt to discover the reason for the decline in DF at MCU, SRNL was tasked with analyzing numerous Caustic Wash Tank (CWT) and chemical feed samples. 


\title{
LIST OF ABBREVIATIONS
}

\author{
CWT - Caustic Wash Tank \\ DF - decontamination factor \\ DSS - Decontaminated Salt Solution \\ ESS - Extraction, Scrub, Strip \\ IC - Ion Chromatography \\ ICPES - Inductively Coupled Plasma Emission Spectroscopy \\ FTIR - Fourier transform infra-red spectroscopy \\ HPLC - High Performance Liquid Chromatography \\ ISDP - Integrated Salt Disposition Project \\ MCU - Modular Caustic-Side solvent extraction Unit \\ SE - Strip Effluent \\ SHT - Solvent Hold Tank \\ SRNL - Savannah River National Laboratory \\ SVOA - Semi Volatile Organic Analysis \\ TOA - trioctylamine
}




\subsection{Introduction}

Solvent Hold Tank (SHT) samples are sent to Savannah River National Laboratory (SRNL) to examine solvent composition changes over time. ${ }^{2}$ On April 12, 2011, Operations personnel delivered six samples from the SHT (MCU-11-314 through -319) for analysis. These samples are intended to verify that the solvent is within the specified composition range. These samples were pulled shortly after the previous solvent adjustment on April 7, 2011.

Since the facility has observed a decline in cesium decontamination factor (DF) recently (average of 161 against a target of 200), the customer also requested that SRNL further examine the solvent sample, and confirm that $\mathrm{F} / \mathrm{H}$ lab ${ }^{137} \mathrm{Cs}$ measurements are crosschecking with comparable SRNL ${ }^{137} \mathrm{Cs}$ measurements. SRNL was also given twelve CWT samples; MCU-11-863, MCU-11-864, MCU-11-865, MCU-11-866, MCU-11-886, MCU-11-887, MCU-11-888, MCU-11-889, MCU-11-898, MCU-11-899, MCU-11-903, and MCU-11-904, and samples from the chemical feeds (i.e., caustic wash, scrub acid and strip acid).

\subsection{Experimental Procedure}

Residual sample (both aqueous and organic portions) from the first set of analyses was retained in the Shielded Cells. Further samples of this material were removed without alteration.

CWT and chemical feeds samples were used as received.

Details for the work are contained in a controlled laboratory notebook. ${ }^{3}$

\subsection{Results and Discussion}

Of the original $\sim 60 \mathrm{~mL}$ of SHT sample sent to SRNL, $\sim 10 \mathrm{~mL}$ was aqueous, and $\sim 50 \mathrm{~mL}$ was organic. We did not analyze (other than $\mathrm{pH}$ ) the aqueous phase in the prior document.

For this study, we sent samples of the aqueous phase for trioctylamine content, ion chromatography (IC anions), and Inductively Coupled Plasma Emission Spectroscopy (ICPES).

Samples of the organic phase were digested and then analyzed by ICPES and Inductively Coupled Plasma Mass Spectroscopy (ICPMS). 
3.1 Aqueous Phase Results

The complete set of aqueous phase results is listed in Table 1.

Table 1. Complete Aqueous Phase Results

\begin{tabular}{|c|c|}
\hline Analyte & Result (mg/L) \\
\hline $\mathrm{pH}$ & $7 \mathrm{pH}$ units \\
\hline $\mathrm{Cl}^{-}$ & 13 \\
\hline $\begin{array}{c}\mathrm{F}^{-}, \text {formate, } \mathrm{NO}_{3}{ }^{-}, \mathrm{NO}_{2}{ }^{-}, \mathrm{Br}^{-}, \\
\mathrm{PO}_{4}{ }^{3-}, \mathrm{SO}_{4}{ }^{2-}, \text { oxalate }\end{array}$ & $\mathrm{All}<10$ \\
\hline $\mathrm{Na}$ & 18.2 \\
\hline $\mathrm{P}$ (from $\mathrm{PO}_{4}{ }^{3-}$ ) & 1.39 \\
\hline $\mathrm{S}$ (from $\mathrm{SO}_{4}{ }^{2-}$ ) & $<7.5$ \\
\hline Trioctylamine (TOA) & 620 \\
\hline
\end{tabular}

In theory, the aqueous phase should consist of entrained caustic wash if present from second phase entrainment during the process, which is a $0.01 \mathrm{M} \mathrm{NaOH}$ solution $(\mathrm{pH}=12)$. However, the very low $\mathrm{pH}$, IC, and ICPES results indicate the aqueous phase is very close to pure water. The material is not entrained caustic wash, or the caustic wash is greatly diluted - the $\mathrm{pH}$ difference between measured and theoretical would suggest 5 orders of magnitude of dilution. Given that the Solvent Hold Tank (SHT) accumulated aqueous carryover during operations, it is highly improbable that any aqueous phase from that tank would have a $\mathrm{pH}$ near that of pure water. Instead, the results suggest that flush water was present in the sample lines, and some of it ended up in the SHT samples.

The TOA result is far greater than what the solubility should be. The expected solubility of TOA in water is $2.4 \mathrm{E}-08 \mathrm{M}$, or $0.0085 \mathrm{mg} / \mathrm{L} .{ }^{4}$ (The solubility in caustic wash is at least $\sim 5 \mathrm{X}$ lower.) Therefore, we consider the TOA result very suspect and SRNL is in the process of submitting a sample for reanalysis.

\subsection{Organic Phase Results}

A sample of the organic phase was digested via a PARR bomb method and the digestate was sent forward for ICPES and ICPMS analyses. The significant ICPES results are listed in Table 2. 
Table 2. Digested Organic Phase ICPES Results

\begin{tabular}{|c|c|c|c|}
\hline Analyte & Result (mg/L) & Analyte & Result (mg/L) \\
\hline $\mathrm{Al}$ & $<26.9$ & $\mathrm{Mg}$ & 30.9 \\
\hline $\mathrm{Ca}$ & 106 & $\mathrm{Na}$ & 732 \\
\hline $\mathrm{Cr}$ & 14.2 & $\mathrm{Ni}$ & 27.0 \\
\hline $\mathrm{Cu}$ & 42.0 & $\mathrm{Si}$ & 282 \\
\hline $\mathrm{Fe}$ & 74.9 & $\mathrm{Zn}$ & 15.8 \\
\hline
\end{tabular}

The analytical uncertainty of the ICPES is $10 \%$.

The significant ICPMS results are listed in Table 3.

Table 3. Digested Organic Phase ICPMS Results

\begin{tabular}{|c|c|}
\hline Analyte & Result (mg/L) \\
\hline${ }^{85} \mathrm{Rb}$ & 0.099 \\
\hline${ }^{88} \mathrm{Sr}$ & 0.312 \\
\hline${ }^{133} \mathrm{Cs}$ & 0.577 \\
\hline${ }^{235} \mathrm{U}$ & 0.0143 \\
\hline${ }^{238} \mathrm{U}$ & 0.0185 \\
\hline${ }^{239} \mathrm{Pu}$ & 0.158 \\
\hline${ }^{240} \mathrm{Pu}$ & 0.0101 \\
\hline
\end{tabular}

The analytical uncertainty if the ICPMS is $20 \%$.

Finally, a Cold Vapor mercury (CV-Hg) analysis was performed on the digestate (see Table 4).

Table 4. Digested Organic Phase CV-Hg Result

\begin{tabular}{|c|c|}
\hline Analyte & Result (mg/L) \\
\hline $\mathrm{Hg}$ & $<8.85$ \\
\hline
\end{tabular}

As a whole, the digested sample results are very problematic. For example, we know from analysis of the source material ${ }^{5}$ that the ${ }^{235} \mathrm{U}:{ }^{238} \mathrm{U}$ mass ratio is $\sim 1: 90$. However, in the results for this sample, the mass ratio is $\sim 3: 4$. As there is no conceivable mechanism to selectively increase the ${ }^{235} \mathrm{U}$ concentration, we have to consider other reasons for this ratio. 
Therefore, we strongly consider that any of the digested solvent results are compromised. SRNL is considering reanalyzing a sample under more controlled conditions, and crosschecking the data with analyses that do not require digestions, such a plutonium analyses.

\subsection{FTIR Analyses of Solvent Samples}

SRNL performed Fourier transform infrared (FTIR) spectroscopy on the composite solvent sample (MCU-11-314/315/316/317/318/319 composite). Figure 1 contains a spectrum for this composite (spectrum "A"), and a spectrum for a freshly prepared sample solvent with "nominal" composition (spectrum "B"), and the difference of the two spectra. The residual peaks suggest several possible functionalities. The peak at $1375 \mathrm{~cm}^{-1}$ has been routinely seen in samples with nitric acid, and so may be indicative of free nitrate. ${ }^{6}$ An aliphatic nitrate group is a possible identification for the peak at $1384 \mathrm{~cm}^{-1} .7$ The peak at $1465 \mathrm{~cm}^{-1}$ could be due to the aliphatic $-\mathrm{CH}_{2}$ - groups attached to an organo-nitrate, but this peak is very close to peaks from Isopar ${ }^{\mathrm{TM}} \mathrm{L}$, so this assignment is tentative at best.

Figure 2 shows difference spectra for prior SHT samples compared to the nominal, or standard, solvent composition. The difference spectra show three remaining peaks at 1467, 1376 and $1364 \mathrm{~cm}^{-1}$ sometimes pointing downward (reflecting depletion) or upward (reflecting excess) associated with the bending vibrations of Isopar ${ }^{\circledR} \mathrm{L}$. Also shown is a new peak at $1384 \mathrm{~cm}^{-1}$ (shown by the dashed line) in the November 2010 spectrum and more intense in the April 2011 spectrum.

Figure 3 provides the difference spectra for April 2011 SHT sample composite compared against reference spectra of bis(2-ethylhexyl)phthalate and sec-butyl phenol. We can see that there is no match, and therefore the new peaks in the April 2011 SHT sample composite are not due to either of these two commonly supposed impurities. A previous document examines the identity of other possible organic contaminants in all of the Tank Farm storage. ${ }^{8}$ While SRNL has not has the time to eliminate all the possibilities identified in that document, we can say that alcohols and ketone impurities are not present. Future work will focus on the possibility of soap-like species such as sulfonates. 


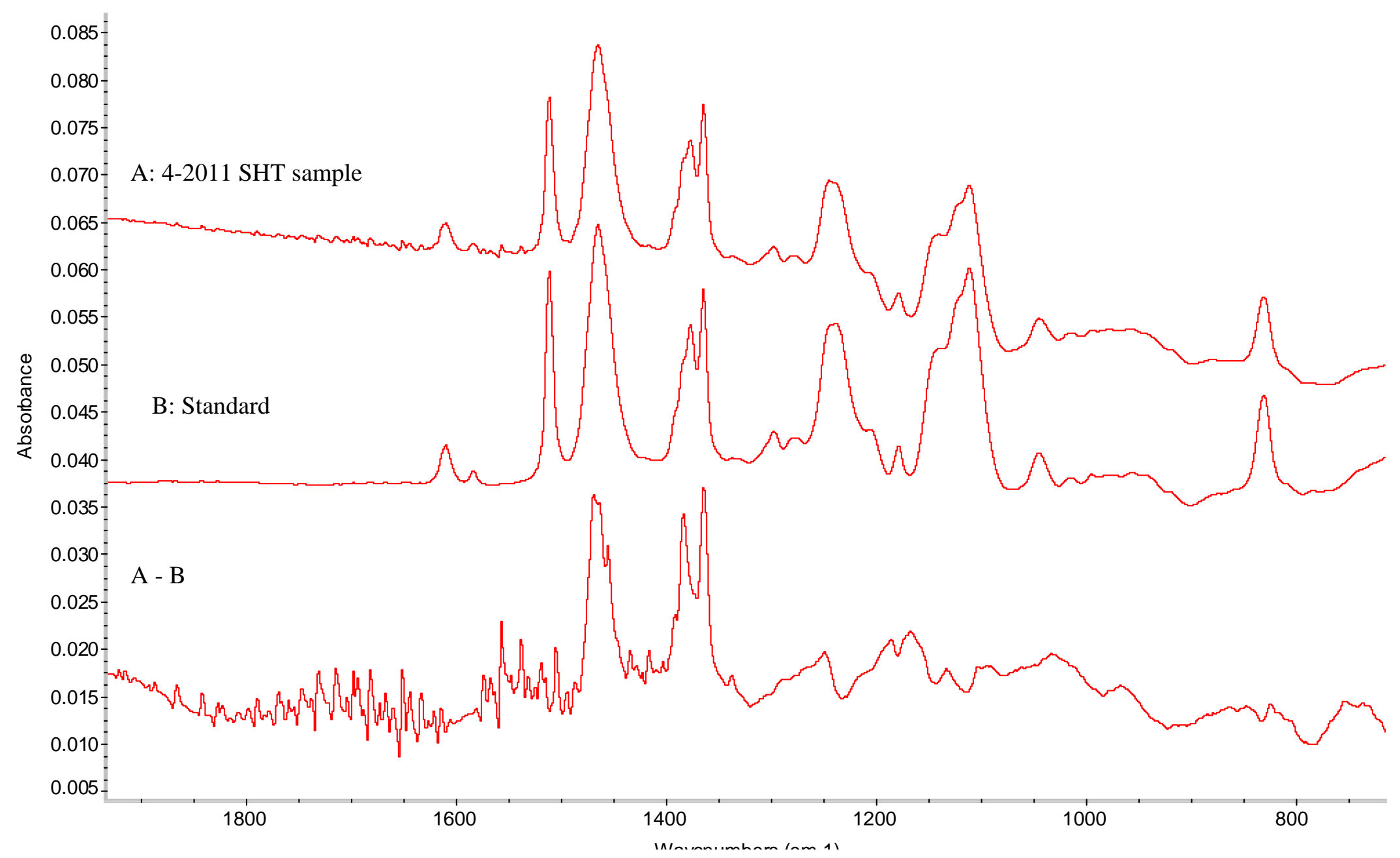

Figure 1. FTIR spectra of composite Solvent Hold Tank sample (A) and of a freshly prepared solvent with "standard" or "nominal" composition (B). Also shown is the difference spectrum. 


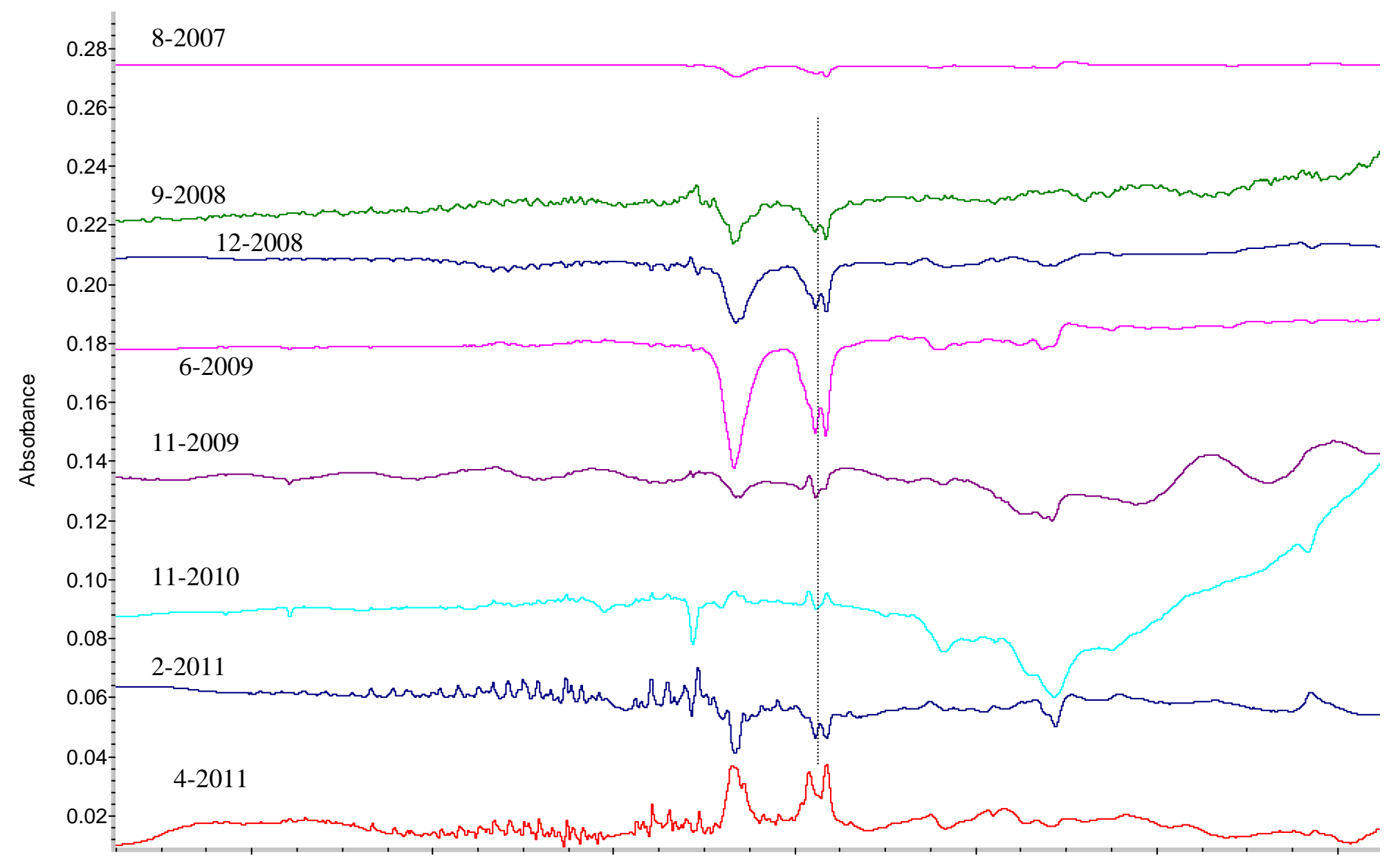

Figure 2. This figure shows the spectra difference between the SHT samples collected since 2007 and a control solvent containing nominal concentrations of CSSX components. 


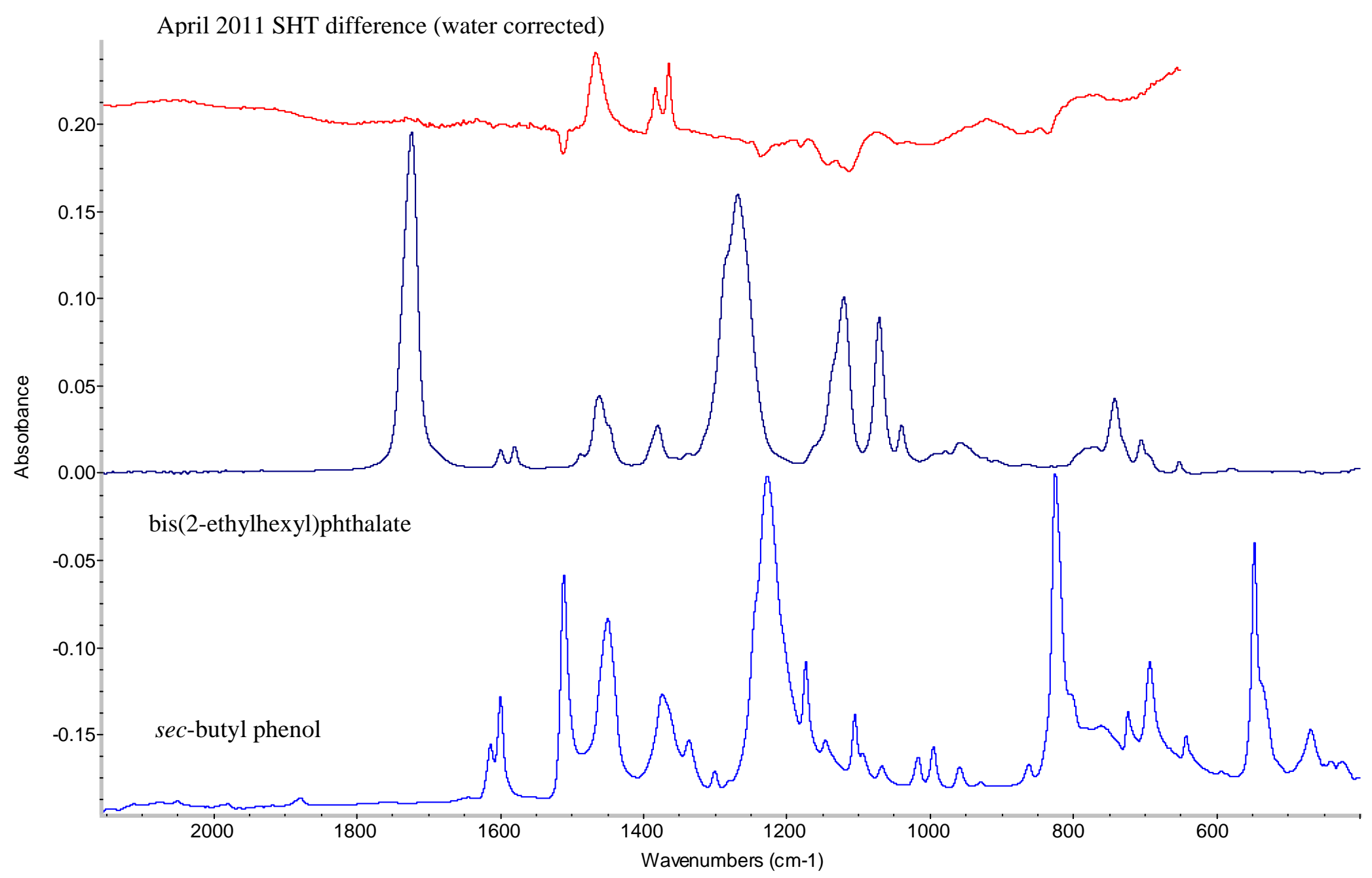

Figure 3. Attempt to identify residual peaks in solvent sample. 
3.4 SRNL and F/H Sample Cross-check

At a customer request, SRNL performed a cross-check of ${ }^{137} \mathrm{Cs}$ sample results from SRNL and F/H Lab. As the same samples are not shared between SRNL and F/H lab, we must instead compare samples that are collected closest in time to each other. Using this methodology, we located six sample results for each of the Decontaminated Salt Solution (DSS) and Strip Effluent (SE) samples that were “common” to both labs. Table 5 shows the comparison of result.

Table 5. SRNL and F/H Lab Comparison

\begin{tabular}{|r|c|c|}
\hline SRNL Sample ID & SRNL Result (dpm/mL) & F/H Lab Result (dpm/mL) \\
\hline \multicolumn{3}{|c|}{ DSS Samples } \\
\hline MCU-10-500 & $7.42 \mathrm{E}+05$ & $8.68 \mathrm{E}+05$ \\
\hline MCU-10-684 & $6.04 \mathrm{E}+05$ & $6.69 \mathrm{E}+05$ \\
\hline MCU-11-33 & $8.54 \mathrm{E}+05$ & $9.33 \mathrm{E}+05$ \\
\hline MCU-11-133 & $6.41 \mathrm{E}+05$ & $7.74 \mathrm{E}+05$ \\
\hline MCU-11-247 & $1.05 \mathrm{E}+06$ & $1.19 \mathrm{E}+06$ \\
\hline MCU-11-361 & $9.11 \mathrm{E}+05$ & $1.04 \mathrm{E}+06$ \\
\hline average & $8.00( \pm 1.70) \mathrm{E}+05$ & $9.12( \pm 1.87) \mathrm{E}+05$ \\
\hline \multicolumn{3}{|c|}{ SE Samples } \\
\hline MCU-10-600 & $1.91 \mathrm{E}+09$ & $1.90 \mathrm{E}+09$ \\
\hline MCU-10-652 & $2.10 \mathrm{E}+09$ & $2.08 \mathrm{E}+09$ \\
\hline MCU-11-37 & $1.93 \mathrm{E}+09$ & $2.01 \mathrm{E}+09$ \\
\hline MCU-11-137 & $1.94 \mathrm{E}+09$ & $1.96 \mathrm{E}+09$ \\
\hline MCU-11-251 & $2.05 \mathrm{E}+09$ & $1.89 \mathrm{E}+09$ \\
\hline MCU-11-362 & $1.99 \mathrm{E}+09$ & $2.04 \mathrm{E}+09$ \\
\hline average & $1.99( \pm 0.0764) \mathrm{E}+09$ & $1.98( \pm 0.0741) \mathrm{E}+09$ \\
\hline
\end{tabular}

The uncertainty for both the SRNL DS and SE ${ }^{137}$ Cs results are 5\%. For the F/H Lab results, the DS analytical uncertainty is $3.2 \%$, and the uncertainty of the SE samples is $7.7 \%$.

There is very good sample correlation between SRNL and F/H Lab results. While there appears to be a negative bias for the SRNL DS results compared to the F/H Lab DS results, for both the DSS and SE sample, the averages of each set are not statistically different. Even more, the agreement in the SE samples is outstanding.

\subsection{CWT Sample Results}

A total of 16 CWT samples were pulled from the CWT and transferred into a radiological hood and sampled. These samples were pulled from MCU during the period of August $22^{\text {nd }}$ to September $5^{\text {th }}$. These are being analyzed for $\mathrm{pH}$, anion content, ${ }^{137} \mathrm{Cs}$ content, 
and/or ICPES. At the time of this writing, measurements are incomplete and available data is reported. See Tables 6 and 7.

Table 6. $\mathrm{pH}$ and ${ }^{137} \mathrm{Cs}$ results for CWT Samples

\begin{tabular}{|c|c|c|}
\hline Sample ID & pH result & ${ }^{137}$ Cs result $(\mathrm{dpm} / \mathrm{mL})$ \\
\hline MCU-11-863 & $9.0-9.5$ & $3.57 \mathrm{E}+05$ \\
\hline MCU-11-864 & $9.0-9.5$ & not available yet \\
\hline MCU-11-865 & $9.5-10.0$ & not available yet \\
\hline MCU-11-866 & 9.5 & $9.11 \mathrm{E}+05$ \\
\hline MCU-11-886 & 9.5 & not available yet \\
\hline MCU-11-887 & 9.5 & not available yet \\
\hline MCU-11-888 & 9.5 & not available yet \\
\hline MCU-11-889 & 9.5 & $5.74 \mathrm{E}+06$ \\
\hline MCU-11-898 & 9.5 & not available yet \\
\hline MCU-11-899 & 9.5 & not available yet \\
\hline MCU-11-903 & 9.5 & $6.13 \mathrm{E}+06$ \\
\hline MCU-11-904 & 9.5 & not available yet \\
\hline MCU-11-1022 & 10 & not available yet \\
\hline MCU-11-1023 & 10 & not available yet \\
\hline MCU-11-1027 & 10 & not available yet \\
\hline MCU-11-1028 & 10 & not available yet \\
\hline
\end{tabular}

The uncertainty on the ${ }^{137} \mathrm{Cs}$ measurements is $5.00 \%$. The uncertainty on the $\mathrm{pH}$ measurements is $0.5 \mathrm{pH}$ units.

Table 7. ICPES Results (mg/L) for Selected CWT Samples

\begin{tabular}{|c|c|c|c|c|}
\hline Analyte & MCU-11-1022 & MCU-11-1023 & MCU-11-1027 & MCU-11-1028 \\
\hline $\mathrm{Al}$ & 0.432 & 0.478 & 0.51 & 0.473 \\
\hline $\mathrm{B}$ & 0.237 & 0.104 & 0.205 & 0.265 \\
\hline $\mathrm{Ba}$ & 0.202 & 0.107 & 0.174 & 0.218 \\
\hline $\mathrm{Ca}$ & 0.216 & 0.16 & 0.211 & 0.239 \\
\hline $\mathrm{Mg}$ & 0.0636 & 0.0734 & 0.034 & 0.0692 \\
\hline $\mathrm{Na}$ & 232 & 249 & 233 & 256 \\
\hline $\mathrm{Si}$ & 4.33 & 3.2 & 3.82 & 4.75 \\
\hline $\mathrm{Sr}$ & 0.0024 & 0.0028 & 0.0022 & 0.0028 \\
\hline
\end{tabular}

The uncertainty of the ICPES results is $10 \%$. 
The $\mathrm{pH}$ results all indicate that the caustic is being consumed more than expected. The caustic wash enters at $\mathrm{pH}=12(0.01 \mathrm{M} \mathrm{NaOH})$ and should not be mostly consumed during operations, exiting near $\mathrm{pH} 11$ or higher under proper operations.

The ${ }^{137}$ Cs measurements show a continual increase in the ${ }^{137} \mathrm{Cs}$ activity is observed, by a factor of $\sim 17 \mathrm{x}$. Cesium in the caustic wash solution is a measure on incomplete stripping. Although we have not explicitly measured the distribution factors for solvent and wash solutions, similar cases studied by ORNL would suggest that the DF for such a system would be $\sim 0.2$, and is furthermore sensitive to the free hydroxide. ${ }^{9}$ From recent data at MCU, we calculate a wash stage DF (organic activity / aqueous activity) of $\sim 0.13$ $(7.99 \mathrm{E}+05 / 6.13 \mathrm{E}+06)$. Given the comparable results, this would seem to indicate the wash contactors are behaving in a predicted manner, at least with regards to cesium partitioning.

The ICPES results indicate that the caustic has the anticipated Na content of $\sim 230 \mathrm{mg} / \mathrm{L}$ $(0.01 \mathrm{M})$. The only other analytes at detectable levels are low enough to be considered tramp material. There is no indication of excessive carryover from scrub and strip into the organic, and then back into the caustic wash.

SRNL is considering the meaning of these results, but further sampling of CWT samples is most likely warranted.

\subsection{Chemical Feed Sample Results}

Samples of the three chemical feeds (caustic wash, scrub acid and strip acid) were sent to SRNL to ensure they were within specifications. The $\mathrm{pH}$ of all three samples was measured. The caustic wash sample was sent for ICPES and free hydroxide measurement, while the scrub and strip acids were sent for anion content. See Tables 8 and 9.

\section{Table 8. pH Results for Chemical Feeds Analysis}

\begin{tabular}{|c|c|}
\hline Chemical Feed & $\mathrm{pH}$ Result \\
\hline Caustic Wash Feed & 12 \\
\hline Scrub acid & $<1$ \\
\hline Strip acid & 3 \\
\hline
\end{tabular}

The uncertainty on the $\mathrm{pH}$ measurements is $0.5 \mathrm{pH}$ units.

The measured $\mathrm{pH}$ values are as expected. Caustic wash is $0.01 \mathrm{M} \mathrm{NaOH}(\mathrm{pH}=12)$, the strip acid is $0.001 \mathrm{M} \mathrm{HNO}_{3}(\mathrm{pH}=3)$ and the scrub acid is $0.05 \mathrm{M} \mathrm{HNO}_{3}(\mathrm{pH}=0.9)$. 
Table 9. Selected Results (mg/L) for Chemical Feeds

\begin{tabular}{|c|c|c|c|}
\hline Analyte & scrub & strip & caustic wash \\
\hline $\mathrm{Al}$ & & & 0.363 \\
\hline $\mathrm{B}$ & & & $<0.081$ \\
\hline $\mathrm{Ba}$ & & & $<0.025$ \\
\hline $\mathrm{Ca}$ & & & 0.349 \\
\hline $\mathrm{Mg}$ & & & 0.007 \\
\hline $\mathrm{Na}$ & & & 264 \\
\hline $\mathrm{Si}$ & & & 1.43 \\
\hline $\mathrm{Sr}$ & & 66 & 0.0056 \\
\hline nitrate & 3760 & & $<0.005 \mathrm{M}$ \\
\hline Free $\mathrm{OH}$ & & & \\
\hline
\end{tabular}

The analytical uncertainties on the ICPES and IC Anions are 10\%.

The scrub acid possesses the anticipated concentration of nitrate $(3760 \mathrm{mg} / \mathrm{L}-0.0606 \mathrm{M}$ versus a target of $0.05 \mathrm{M}$ ), while the strip acid is also as expected $(66 \mathrm{mg} / \mathrm{L}-0.00106 \mathrm{M}$ versus a target of $0.001 \mathrm{M}$ ). The caustic wash contains sodium at $0.0115 \mathrm{M}$ concentration, which is close to what is found in the CWT samples (Table 7) and the target concentration $(0.01 \mathrm{M})$. The other analytes in the ICPES are probably tramp material. The Free hydroxide result is troubling; indicating the Free $\mathrm{OH}$ is too low to begin with. However, this does not agree with the measurement of the caustic wash by $\mathrm{pH}$ paper $(\mathrm{pH}=12$, or Free $\mathrm{OH}=0.01 \mathrm{M})$. It may be that the sensitivity of the Free Hydroxide analysis is poor at these levels of analyte.

None of the results of the chemical feeds indicate a serious deviation from their intended composition. Furthermore, we can also say that there appears to be no macroscopic dilution from chemical feed to CWT, which means the aqueous carryover into the solvent during strip is minimal.

\subsection{Conclusions}

The aqueous phase of material that was in the SHT samples is most likely from some sort of flush or process water, and is not indicative of any of the feeds or outputs from MCU.

The digested organic sample gives results that appear to indicate the sample or the analysis is compromised. Any use of the digested solvent sample results should be carefully considered pending further analyses by SRNL. 
SRNL recommends re-analyzing the solvent sample with non-digestion cross-checks, and further, we recommend digesting samples of the current SHT quarterly sample from September.

With regards to the ${ }^{137}$ Cs sample cross-checks, we find that our limited dataset provides no reason for concern. The results between SRNL and F/H Lab show good agreement.

The caustic wash samples all exhibit $\mathrm{pH}$ values that are lower than expected.

Furthermore, the ${ }^{137} \mathrm{Cs}$ activity in these samples increases with time. Further sampling is necessary to determine if this effect is ongoing. For the few samples with ICPES results, there is no indication of serious deviation from expected results, and no indication of gross inorganic contamination.

The chemical feeds exhibit the expected $\mathrm{pH}$ values, and available ICPES and IC Anions results we have indicate they are all within expectations. The single low result from the free hydroxide measurement is troubling, but is not matched by the measurement by $\mathrm{pH}$ strip, which gives the expected results.

To confirm or deny the presence of any possible organic contaminants, SRNL recommends combining the CWT samples and extracting the composite with dichloromethane. This extract can then be forwarded for analysis to detect any organic impurities. This approach can also be done on the chemical feed samples but is considered of secondary importance to examining the process sample. 
SRNL-STI-2011-00591

Revision 0

\subsection{References}

${ }^{1}$ T. B. Peters, A. L. Washington, F. F. Fondeur, and S. D. Fink, "Solvent Hold Tank Sample Results for MCU-11-314, MCU-11-315, MCU-11-316, MCU-11-317, MCU-11-318 and MCU-11-319”, SRNL-STI2011-00301,Rev. 0, June, 2011.

${ }^{2}$ W. M. Matthews, HLW-CRF-10006, Rev. 0, May 18, 2010.

${ }^{3}$ T. B. Peters, "ISDP3", SRNL-NB-2009-00153, October 28, 2009.

${ }^{4}$ B. A. Moyer, S. D. Alexandratos, P. V. Bonnesen, G. M. Brown, J. E. Caton, Jr., L. H. Delmau, C. R. Duchemin, T. J. Haverlock, T. G. Levitskaia, M. P. Maskarinec, F. V. Sloop, Jr., and C. L. Stine, "CausticSide Solvent Extraction Chemical And Physical Properties Progress in FY 2000 and FY 2001,” ORNLTM-2001-285 (Table 4.5), February 2001.

${ }^{5}$ S. E. Campbell, "Blend Evaluation for Tank 49H Feed for ISDP Salt batch 3", X-ESR-H-00209, March, 2010.

${ }^{6}$ Richard A. Nyquist and Ronald O'Kagel, Academic Press New York, 1971 (spectrum \# 155 and 156)

${ }^{7}$ T. Windblom, "Reactions in the System Nitro-Celluose/Diphenylamine with Special Reference to the Formation of a Stabilizing Product Bonded to Nitro-Celluose", Comprehensive Summaries of Uppsala Dissertations from the Faculty of Science and Technology 935, Acta Universitatis Upsaliensis, 2004.

${ }^{8}$ D. D. Walker, “Organic Compounds In Savannah River Site High-Level Waste”, WSRC-TR-2002-00391, Rev.0, September 30, 2002.

${ }^{9}$ L. H. Delmau, D. A. Bostick, T. J. Haverlock, B. A. Moyer, “ Caustic-Side Solvent Extraction:

Extended Equilibrium Modeling of Cesium and Potassium Distribution Behavior”, ORNL/TM-2002/116, May 2002. 


\section{Distribution:}
A. B. Barnes, 999-W
S. D. Fink, 773-A
B. J. Giddings, 786-5A
C. C. Herman, 999-W
S. L. Marra, 773-A
F. M. Pennebaker, 773-42A
E. J. Freed, 704-56H
D. J. Martin, 241-152H
M. W. Geeting, 241-152H
S. P. McLeskey, 241-152H
B. A. Gifford, 704-56H
S. A. Thomas, 703-46A
T. B. Peters, 773-42A
C. A. Nash, 773-42A
M. R. Poirier, 773-42A
F. F. Fondeur, 773-A
P. R. Jackson, 703-46A 